\title{
EVALUATING THE EFFECTIVENESS OF PATIENT EDUCATION TO COPE UP DEPRESSION IN MENOPAUSAL STAGE
}

\author{
GANAPATHY SANKAR $\mathbf{U}^{1}$, MONISHA ${ }^{1 *}$, CHRISTOPHER AMALRAJ VALLABA DOSS ${ }^{2}$, PALANIVEL RM ${ }^{3}$
}

${ }^{1}$ SRM College of Occupational Therapy, SRM Institute of Science and Technology, Kattankulathur, Chennai, Tamil Nadu, India. ${ }^{2}$ College of Medicine, Imam Abdulrahman Bin Faisal University, P. O. Box 1982, Dammam 31441, Saudi Arabia. ${ }^{3}$ Deanship of Quality and Academic Accreditation, Imam Abdulrahman Bin Faisal University, P. O. Box 1982, Dammam 31441, Saudi Arabia. Email: dreamsfuture000@gmail.com

Received: 02 February 2020, Revised and Accepted: 09 March 2020

\section{ABSTRACT}

Objectives: The aim of the study was to assess the impact of education to combat depression in the menopausal stage.

Methods: Twenty menopausal women, aged 50-55 years were recruited through convenience sampling procedure from Kancheepuram. Zung selfrating depression scale was administered to all the participants.

Results: It revealed that there was a statistical difference in post-test after education on depression ( $\mathrm{t}=13.413$; $\mathrm{p}=0.00)$ on menopausal women.

Conclusion: Depression is the common psychological symptoms that affect the women at menopausal age. The severity is due to a lack of knowledge about the symptoms and a lack of awareness to cope with the psychological symptoms.

Keywords: Depression, Anxiety, Menopause.

(C) 2020 The Authors. Published by Innovare Academic Sciences Pvt Ltd. This is an open access article under the CC BY license (http://creativecommons. org/licenses/by/4. 0/) DOI: http://dx.doi.org/10.22159/ajpcr.2020.v13i5.37102

\section{INTRODUCTION}

Researchers always pay interest regarding menopause in the medical field. International menopause society was recognized in 1978 during the second menopause congress. Paris and France structured the first international congress on menopause during 1976. In different areas of the world, menopausal symptom varies, for example, hot flush in the west, shoulder ache in Japan, and poor eyesight in India. West countries have higher menopausal age than in India [1].

Menopause is defined as the permanent cessation of menstruation and ovulation due to ovarian failure. Menstrual cycles stop permanently suddenly due to the usual reduction of ovarian oocytes. It marks the end of a woman's fertility. Menopause has major changes in several endocrine systems. The hormone system also maintains the musculoskeletal system and controls the growth during adolescence. Menopause occurs naturally between 42 and 58 years. Lifestyle changes, menopause hormone therapy, or other supplementations such as calcium Vitamin $\mathrm{D}$ and micronutrients are the remedies that prevent disease that cause menopause [2]. Menopause is less in western countries than in India. Women undergo more changes in bodily symptoms, which may be due to lower levels of hormonal secretion. Body changes and symptoms can be adopted by a healthy lifestyle.

Increased stress, anxiety, and fear are frequently seen in middle age. Hot flashes, sweating, and other symptoms of menopause may cause disruptions. There may also be emotional changes such as worries about getting older, loss of family members, or children leaving home. Isolation or frustration occurs during menopause for some women [3]

Psychological symptoms are due to hormonal changes during menopause. A study that was conducted over a period of time stated that during early and mid perimenopause, there was an increased difference in estrogen level for women developing depression. The most common symptom observed in menopause is anxiety and an unusual feeling of nervousness. Insomnia and fatigue can be precipitating factors [4].
Some psychological symptoms occur due to physical changes. Hormonal changes can be directly linked with these symptoms that take place during menopause. Changes brought in physical lifestyle could decrease the instance of psychological symptoms [5].

\section{METHODOLOGY}

The motive of the study was explained to 60 women who were interviewed personally from June 2016 to June 2017 and informed consent was obtained. Twenty-five women were included in the control $(n=25)$ group and experimental $(n=25)$ group according to the specific inclusion and exclusion criteria. The person with menopausal symptoms of age group 40-50 years was included and women who are working in the health professional field and with visual and hearing impairment were excluded from the study. The pre-test was done using self rated depression scale (SDS) for both groups. The experimental group received intervention for the management of symptoms. The control group did not receive the intervention. The post-test was collected using SDS from both the groups. Data were analyzed. Education was given individually for $30 \mathrm{~min}$ through computer assistance for 8 weeks with a total of 12 sessions. Where the first $15 \mathrm{~min}$ was education and the next $15 \mathrm{~min}$ was a practical explanation of education. The therapy session included relaxation techniques, guided imagery, mindfulness meditation, and muscle relaxation techniques. The control group was not given any education (Fig.1).

\section{RESULTS}

Paired " $\mathrm{t}$ " test was used to identify the effectiveness of education on depression among women in the menopausal stage. The results discovered that there was a significant difference in depression $(\mathrm{t}=10.534 ; \mathrm{p}=0.00)$ after education

To evaluate the pre and post-test scores of depression in the control group paired "t," the test was used. The result revealed that there was a significant difference in depression (Tables 1-3). 


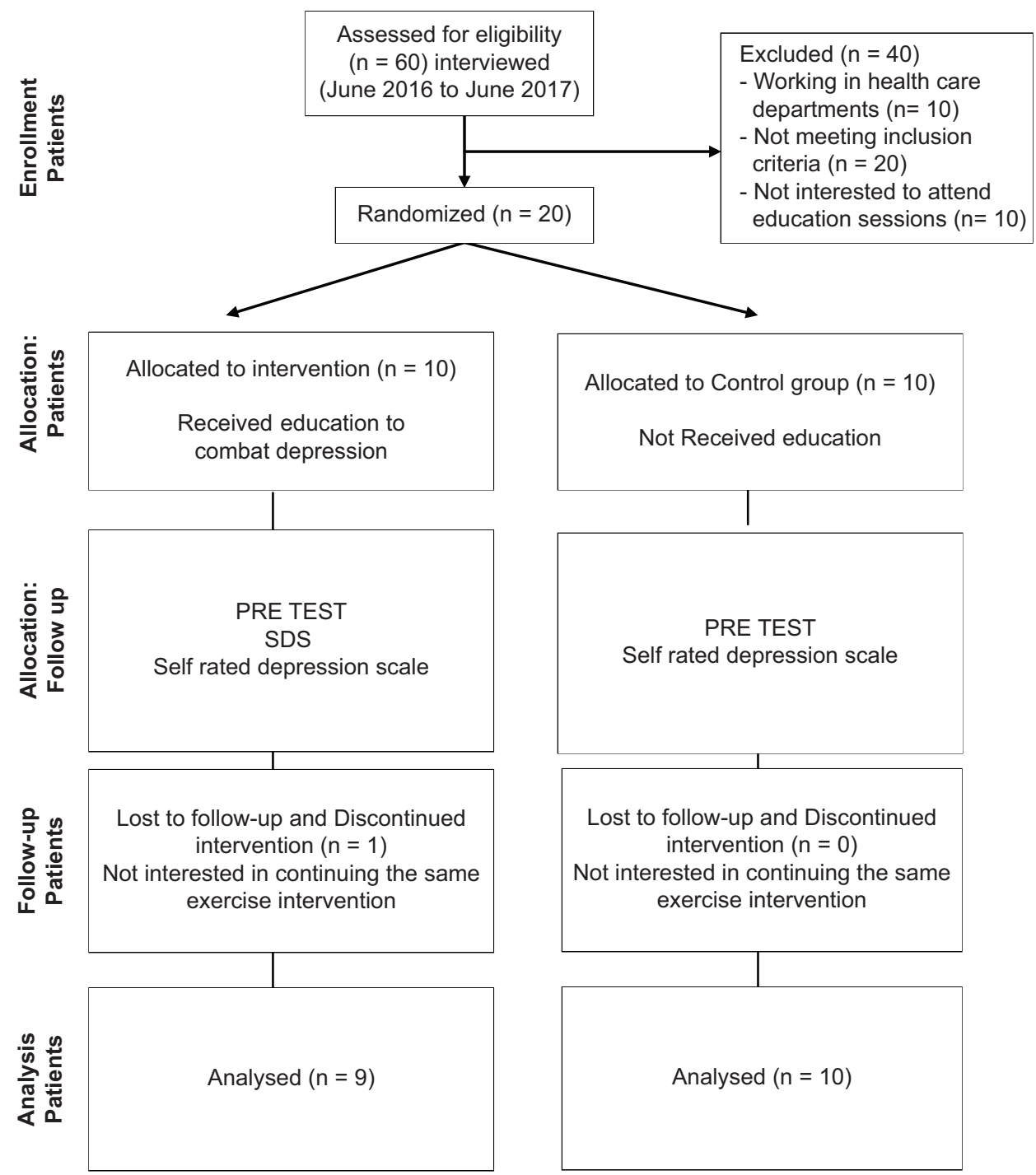

Fig. 1: Modified CONSORT flow diagram

Table 1: Demographic distribution of variables

\begin{tabular}{llllll}
\hline \multirow{2}{*}{ Age } & Housewife & Working & \multicolumn{3}{c}{ No. of children } \\
\cline { 3 - 6 } & & & $\mathbf{1}$ & $\mathbf{2}$ & $\mathbf{3}$ \\
\hline $40-45$ & 9 & 3 & 1 & 5 & 6 \\
$46-50$ & 3 & 5 & 1 & 4 & 3 \\
Total & 12 & 8 & & & \\
\hline
\end{tabular}

Table 2: Effect of education on depression among menopausal women

\begin{tabular}{llllll}
\hline Variable & Pre-test & & Post-test & “t” & "p" \\
\cline { 2 - 3 } & $\mathbf{M}$ & & $\mathbf{M}$ & & \\
\hline Depression & 50.22 & 39.75 & 10.534 & 0.00 \\
\hline
\end{tabular}

Table 3: Comparison of pre-test and post-test score of the control group

\begin{tabular}{|c|c|c|c|c|}
\hline \multirow[t]{2}{*}{ Variable } & Pre-test & Post-test & “t” & “p” \\
\hline & $\mathbf{M}$ & M & & \\
\hline Depression & 40.22 & 41.00 & 5.001 & 0.00 \\
\hline
\end{tabular}

\section{DISCUSSION}

Lifestyle changes, medications, therapy, or a combination is the intervention method to cope with menopausal changes that can naturally relieve conditions such as depression and anxiety (North American Menopause Society). Many women in menopause experience sleep problems. Keeping the bedroom dark, quiet, and cool while you sleep may also help. Regular exercise can help relieve stress while boosting energy and mood [6]. This exercise can be done $30 \mathrm{~min}$ a day for 5 days a week. It is also important to include at least two muscle-strengthening activities sessions on a weekly basis. Tai chi, meditation, and massage are all relaxing activities that can assist in decreasing stress. Simultaneously it can also aid in better sleep during nights. Friends and family members may provide women with valuable social support. It helps to connect them with other women in the community who are also going through menopause. A mental training practice named mindfulness meditation helps the mind to concentrate on the experience of the moments that take place in the present [7]. Breathing exercise, mental imagery, body awareness can also be involved. Guided imagery is a mind-body technique that helps the women to evoke and generate mental research found that various physical and psychosomatic changes occur during menopause. Kwak et al. (2014) found that the group of women in menopause had a remarkably high level of physical and psychosomatic changes than the group of women in around menopause. Further, they concluded that knowledge about menopausal symptoms and management was not adequate. Hence, the current study carried out to identify the 
effectiveness of education to cope with depression during menopause in women. Breathing exercise was given to the participants for $30 \mathrm{~min}$ a day for 5 days a week; relaxation techniques were taught to the participants to reduce stress, mindfulness meditation was done to experience the positive moments of life in which they will feel relaxed, guided imagery helped the participants to concentrate on positive images which will reduce their pain, stress, and psychological problems $[7,8]$. These educations were very effective for the participants to cope with menopausal symptoms. A previous study (Hunter, 1999) also proved that education given was effective on menopausal women. Hunter, 1999 conducted a study on the evaluation of health education intervention for menopausal women. The knowledge was discussed in the group about menopause, management of stress, and physical habits (smoking, exercise, and diet) which were the intervention used. The author concluded that the intervention given was a highly positive impact on knowledge about menopause $[9,10]$

There was a statistically significant difference between pre- and posttest data of depression in the control group, but the control group has not received any education. Nowadays, social media users are increased worldwide [11,12]. Suddenly, in Tamil Nadu, social media users increased. Social media such as WhatsApp, Facebook, and Instagram have received education about menopausal symptoms. Further, TV, Radio, and Newspapers also play a key role to impart knowledge about menopausal symptoms. This may influence the results of the current state.

\section{CONCLUSION}

Menopausal symptom varies from each and every woman. They undergo various symptoms such as physical and psychological changes. Depression is the most common psychological symptoms that affect the women at menopausal age. Education should be given before the menopausal age occurs to reduce the severity of the psychological symptoms.

\section{ACKNOWLEDGMENT}

I would like to express my heartiest gratitude to Dr. U. Ganapathy Sankar for giving me support and encouragement.

\section{AUTHORS' CONTRIBUTIONS}

I would like to express my heartiest gratitude to the participants, who gave willingness to participate in the study.

\section{CONFLICTS OF INTEREST}

There are no conflicts of interest.

\section{AUTHORS' FUNDING}

Self.

\section{REFERENCES}

1. World Health Organization. Research on Menopause: Report of WHO Scientific Group. Technical Report Series 670. Geneva: World Health Organization; 1981.

2. Vijayalakshmi S, Chandrababu R, Victoria E. Menopausal transition among Northern Indian women. Nitte Univ J Health Sci 2013;3:73-9.

3. Timur S, Sahin NH. The prevalence of depression symptoms and influencing factors among perimenopausal and postmenopausal women. Menopause 2010;17:545-51.

4. Singh A, Pradhan SK. Menopausal symptoms of postmenopausal women in a rural community of Delhi, India: A cross-sectional study. J Midlife Health 2014;5:62-7.

5. Hamilton M. A rating scale for depression. J Neurol Neurosurg Psychiatry 1960;23:56-62.

6. Polisseni AF, de Araújo DA, Polisseni F, Mourão Junior CA, Polisseni J, Fernandes ES, et al. Depression and anxiety in menopausal women: Associated factors. Rev Bras Ginecol Obstet 2009;31:28-34

7. Afshari P, Manochehri S, Tadayon M, Kianfar M, Haghighizade M. Prevalence of depression in postmenopausal women, Jundishapur. J Chronic Dis Care 2015;4:e27521.

8. Unsal A, Tozun M, Ayranci U. Prevalence of depression among postmenopausal women and related characteristics. Climacteric 2011;14:244-51.

9. Li Y, Yu Q, Ma L, Sun Z, Yang X. Prevalence of depression and anxiety symptoms and their influence factors during menopausal transition and postmenopause in Beijing city. Maturitas 2008;61:238-42.

10. Howkins J, Bourne G. Perimenopause, menopause, premature menopause and postmenopausal bleeding. In: Paduvidri VG, Daftary SN, editors. Shaw's Textbook of Gynaecology. $14^{\text {th }}$ ed. India: Elsevier; 2008.

11. Ghogari IS, Jain PS. Development of orally disintegrating tablets of memantine hydrochloride-a remedy for Alzheimer's disease. Int J Appl Pharm 2019;12:147-52.

12. Qushawy M, Nasr A. Solid lipid nanoparticles (SLNS) as Nano drug delivery carriers: Preparation, characterization and application. Int $\mathrm{J}$ Appl Pharm 2019;12:1-9. 